\title{
Ageing Processes in Al-Mg-Si Alloys during Continuous Heating
}

\author{
Yasuya Ohmori, Long Chau Doan* and Kiyomichi Nakai \\ Department of Materials Science and Engineering Ehime University, Matsuyama 790-8577, Japan
}

The precipitation behaviours during continuous heating in the $\mathrm{Al}-\mathrm{Mg}_{2} \mathrm{Si}$ alloys with excess $\mathrm{Mg}$ and Si contents have been investigated by means of Vickers hardness measurements, differential scanning calorimetry and transmission electron microscopy. The first exothermic reaction occurring at the lowest temperatures is due to the annihilation of quenched-in vacancies by the collapse of vacancy clusters and the migration of vacancies to various sinks such as grain boundaries. The prismatic dislocation loops formed by this collapse are frequently observed. The second reaction detected as broad hardening increases with increasing excess Si content and can be interpreted as the formation of solute atom clusters. The sharp and large exothermic reaction inducing the largest hardening corresponds to the precipitation of $\beta^{\prime \prime}$ needles. The following exothermic reaction arises from the precipitation of $\beta-\mathrm{Mg}_{2} \mathrm{Si}$ particles. The formation of $\beta^{\prime}$ and Type-B rods can be recognised in the quasi-binary and the excess $\mathrm{Si}$ at slightly higher temperatures.

(Received September 13, 2001; Accepted December 13, 2001)

Keywords: aluminium-magnesium-silicon alloy, precipitation, $\beta^{\prime \prime}$ needles, $\beta$ - $\mathrm{Mg}_{2}$ Si particles, $\beta^{\prime}$ rods, Type-B precipitates, crystallography, transmission electron microscopy

\section{Introduction}

The precipitation sequence in solution-treated $\mathrm{Al}-\mathrm{Mg}_{2} \mathrm{Si}$ alloys has been reported as: clustering of $\mathrm{Si}$ and $\mathrm{Mg}$ atoms $\rightarrow$ needlelike $\beta^{\prime \prime}$ precipitation $\rightarrow$ transformation of $\beta^{\prime \prime}$ needles to $\beta^{\prime}$ rods $\rightarrow$ stable platelike $\beta-\mathrm{Mg}_{2}$ Si precipitation. ${ }^{1-6)}$ The formation of some other intermediate phases has also been reported. Kanno et al. ${ }^{7,8)}$ demonstrated that cuboid fcc particles with the lattice parameter $a=0.633 \pm 0.005 \mathrm{~nm}$ precipitate in the $\left(\alpha+\mathrm{Mg}_{2} \mathrm{Si}\right) 2$ phase region as a transient phase from $\beta^{\prime}$ rods to $\beta-\mathrm{Mg}_{2} \mathrm{Si}$ plates. Westengen and Ryum ${ }^{9)}$ also observed similar cuboid particles and concluded that they are of equilibrium $\beta-\mathrm{Mg}_{2} \mathrm{Si}$ phase from the energy dispersive X-ray analysis. In the excess Si alloys, however, Matsuda et al. ${ }^{10-13)}$ reported that a hexagonal Type-A phase with $a=0.405$ and $b=0.670 \mathrm{~nm}$, an orthorhombic Type B phase with $a=0.684, b=0.793$ and $c=0.405$ and a hexagonal Type-C phase with $a=1.05$ and $b=0.405 \mathrm{~nm}$ form. The precipitation of $\beta^{\prime \prime}$ and $\beta^{\prime}$ phases has been studied extensively and various models for the crystal structures have been proposed, i.e., monoclinic structures for $\beta^{\prime \prime}$ needles, ${ }^{12,14-19,25)}$ hexagonal structures for $\beta^{\prime}$ rods. ${ }^{2,14,16,17,20,21)}$ Thus, further detailed study will be necessary to specify the structures.

It should also be noted that the precipitation sequence has often been examined by differential scanning calorimetry (DSC) during continuous heating and that the results have been compared in many cases with those obtained by transmission electron microscopy (TEM) for the isothermally aged specimens. The processes in continuous heating, however, will be significantly different from those in isothermal ageing.

The purpose of the present study is, therefore, to clarify the effects of excess $\mathrm{Si}$ and $\mathrm{Mg}$ on the ageing behaviour during continuous heating by means of DSC, TEM and Vickers hardness measurements, systematically.

\footnotetext{
*Graduate Student, Ehime University.
}

Table 1 Chemical composition of Al-Mg-Si alloys (at\%).

\begin{tabular}{lcccc}
\hline Alloy & $\mathrm{Mg}$ & $\mathrm{Si}$ & $\mathrm{Mg}_{2} \mathrm{Si}$ & Excess Si \\
\hline Alloy 1 & 1.48 & 0.48 & 1.44 & -0.26 \\
Alloy 2 & 0.82 & 0.47 & 1.23 & 0.06 \\
Alloy 3 & 1.23 & 0.79 & 1.85 & 0.17 \\
Alloy 4 & 0.88 & 0.85 & 1.32 & 0.41 \\
Alloy 5 & 0.93 & 1.03 & 1.39 & 0.57 \\
\hline
\end{tabular}

\section{Experimental Procedures}

The chemical compositions of the materials used are shown in Table 1. The ingots were homogenised at $833 \mathrm{~K}$ for $12 \mathrm{~h}$ and were rolled to $1.25 \mathrm{~mm}$ thick plates at room temperature. The disklike specimens $1.25 \mathrm{~mm}$ thick and $5 \mathrm{~mm}$ in diameter were machined from the plates for DSC, TEM and hardness measurements. They were solutionized at $833 \mathrm{~K}$ for $30 \mathrm{~min}$ and quenched into iced water. Immediately after quenching, DSC measurements were carried out at constant heating rates between 10 and $50 \mathrm{~K} / \mathrm{min}$ in a dynamic $\mathrm{N}_{2}$ atmosphere to minimise the oxidation following the procedure by Jena et al. ${ }^{22}$ ) The specimens for Vickers hardness measurements and TEM observation were also aged to various temperatures in the same specimen holder of the differential scanning calorimeter. Thus the heating rates for all the specimens were exactly the same. The hardness and TEM specimens were cooled in a dynamic $\mathrm{N}_{2}$ atmosphere after reaching the temperatures. Micro-Vickers hardness measurements were conducted with $300 \mathrm{~g}$ load. Thin foils for TEM were prepared by electrolytic polishing in the mixture of three parts of methanol and one part of $\mathrm{HNO}_{3}$ at $243 \mathrm{~K}$ and were examined in a JEOL-2000EX microscope operating at $200 \mathrm{kV}$.

\section{Experimental Results}

\subsection{Vickers hardness measurements}

Figures 1(a) and (b) show the effects of continuous heating temperature on Vickers hardness for the heating rates of 10 


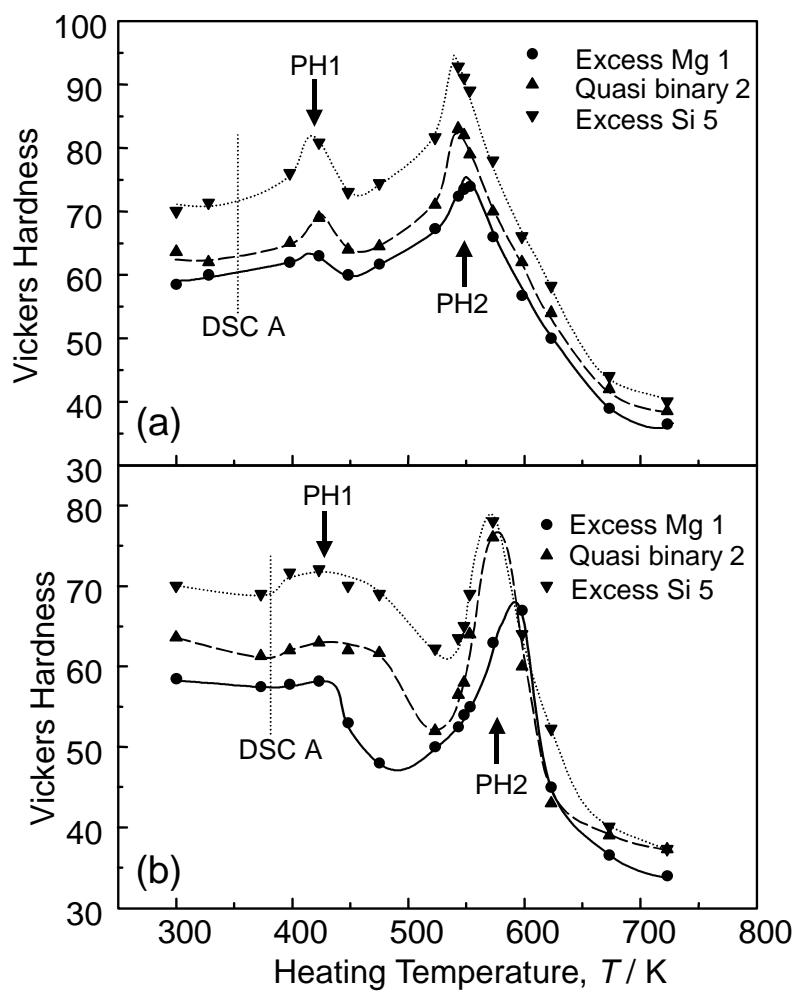

Fig. 1 Effects of heating temperature on Vickers hardnessHeating rate: (a) $10 \mathrm{~K} / \mathrm{min}$ and (b) $50 \mathrm{~K} / \mathrm{min}$.

and $50 \mathrm{~K} / \mathrm{min}$, respectively. The materials used are the excess $\mathrm{Mg}$ (Alloy 1), the quasi-binary (Alloy 2) and the excess Si alloys (Alloy 5). In the case of heating at $10 \mathrm{~K} / \mathrm{min}$, all the specimens exhibited a similar hardening sequence as can be seen in Fig. 1(a), i.e., slight hardening at temperatures between $350-425 \mathrm{~K}$, (this hardening will be referred to as "PH1"), and small softening at temperatures around $450 \mathrm{~K}$, and a sharp and large hardening at temperature around $550 \mathrm{~K}$ (PH2) with the subsequent large drop in hardness. The reaction temperatures displaced to higher temperatures with increasing heating rate as shown in Fig. 1(b). The hardness of the excess Si alloy was much higher than that of the quasi-binary alloy aged ate temperatures below $\mathrm{PH} 2$ but the hardness increment was much reduced in the over-aged condition. In the present study, although the hardness of the excess $\mathrm{Mg}$ alloy decreased in comparison with that of the quasi-binary alloy, Suzuki et $a{ }^{23)}$ reported that the excess $\mathrm{Mg}$ alloy quenched after complete solutionising induces hardness higher than that of the quasi-binary alloy. Such difference may arise from the incomplete solution-treatment, ${ }^{23)}$ because the chemical composition of this alloy was in rather critical region. The peak temperature of PH2 was lowered considerably with increasing excess Si content.

On these figures, the temperatures where the small exothermic reaction A were detected by DSC measurement were superposed. Although the heating rates for both DSC and hardness measurements were exactly the same, some additional ageing might have progressed in the hardness specimens during the cooling in a dynamic $\mathrm{N}_{2}$ atmosphere. This implies that the true temperatures for the hardness peaks should be displaced to higher temperature sides. It should be noted that, even in such situations, the peak temperatures for the

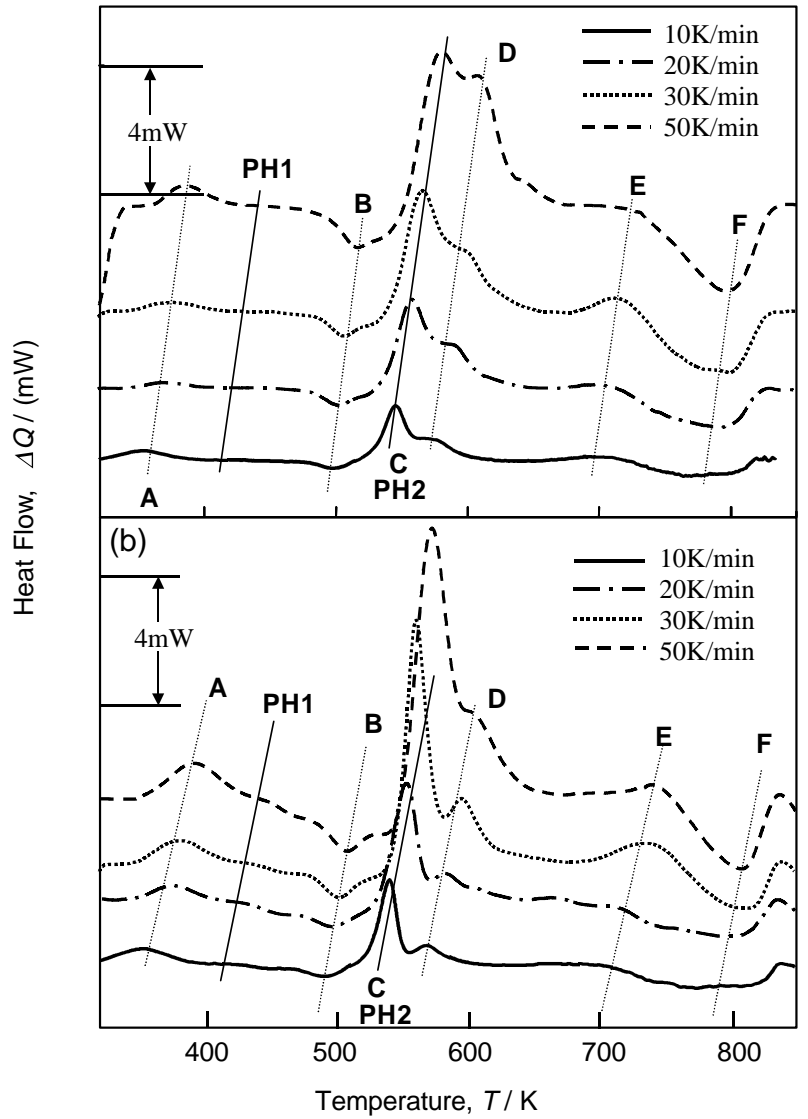

Fig. 2 DSC curves for Alloys 2 and 5 heated at different rates(a) Alloy 2 and (b) Alloy 5.

first slight hardening, $\mathrm{PH} 1$, are clearly separated from those of the reaction A (DSC-A) as can be seen in Fig. 1. Thus, the mechanisms inducing these two reactions may be different.

\subsection{DSC results}

As examples, DSC thermograms at various heating rates from 10 to $50 \mathrm{~K} / \mathrm{min}$ in the alloys 2 and 5 are shown in Figs. 2(a) and (b), respectively. The peak temperatures for PH1 and $\mathrm{PH} 2$ were superposed also on these figures. By examining all the DSC curves, four exothermic reactions, i.e., A, $\mathrm{C}, \mathrm{D}$ and $\mathrm{E}$, and two endothermic reactions, $\mathrm{B}$ and $\mathrm{F}$, were recognised. In the DSC curves for the quasi-binary alloy 2, a diffuse exothermic peak $\mathrm{A}$, an endothermic peak $\mathrm{B}$, a large and sharp exothermic peak $\mathrm{C}$, the following significantly large exothermic peak D, a diffuse peak $\mathrm{E}$ and a broad endothermic peak F can be observed, the peak temperature being displaced to higher temperatures by increasing heating rate from 10 to $50 \mathrm{~K} / \mathrm{min}$ as shown in Fig. 2(a). It should be noted that the PH1 deviates significantly from the peak A to higher temperature side as pointed out in Fig. 1. The $\mathrm{PH} 2$ temperature is in good agreement with that for the peak $\mathrm{C}$.

Since the peak height ratio of the reaction $\mathrm{D}$ to that of $\mathrm{C}$, $h_{\mathrm{D}} / h_{\mathrm{C}}$, is thought to be roughly proportional to the ratio for the amounts of the reactions, $h_{\mathrm{D}} / h_{\mathrm{C}}$ was plotted against excess Si content (Fig. 3). ${ }^{24)}$ The $h_{\mathrm{D}} / h_{\mathrm{C}}$ ratio decreased drastically with increasing excess $\mathrm{Si}$ content above $0.2 \%$. Thus the reaction D may be predominant in the low excess Si alloys.

The area of each peak calibrated by heating rate provides the enthalpy change directly relating to the molar heat and the 


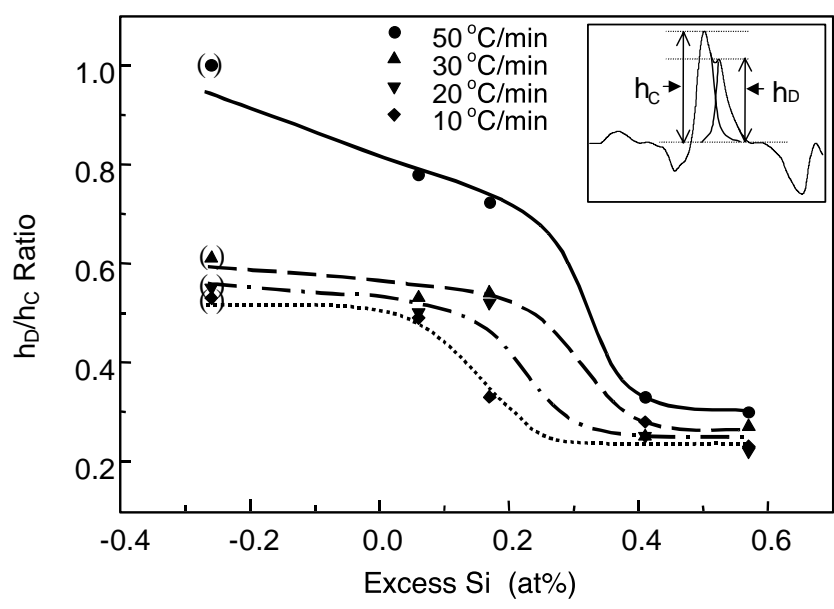

Fig. 3 Effects of excess Si content on the peak height ratio $h_{\mathrm{D}} / h_{\mathrm{C}}$ in the DSC curves.

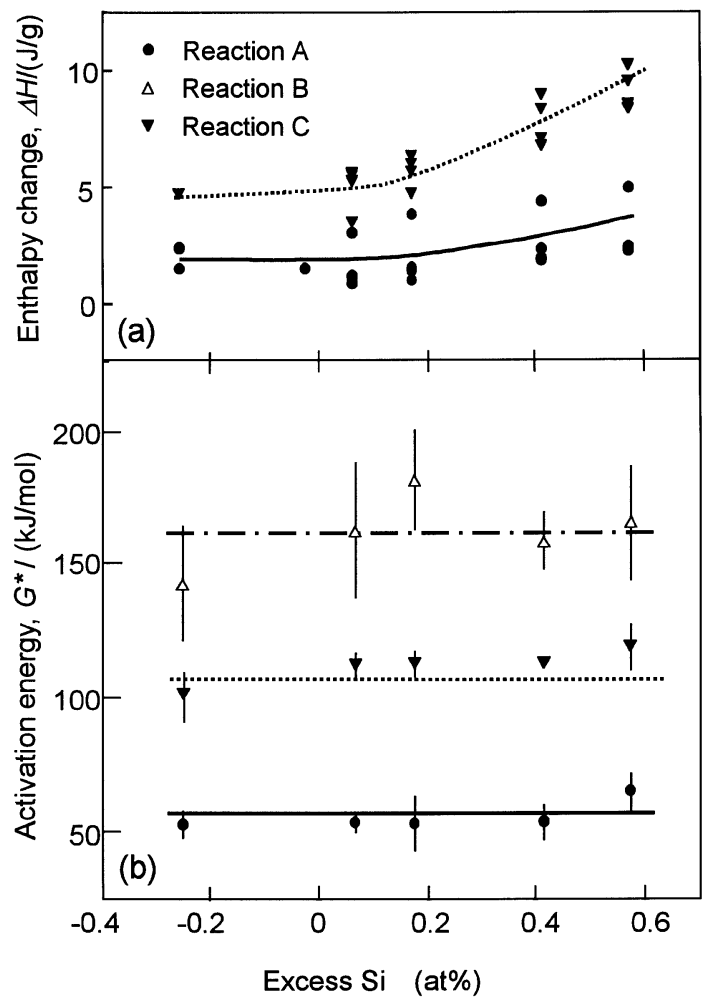

Fig. 4 Effects of excess Si content on the enthalpy changes and the activation energies for peaks A, B and C. (a) Enthalpy changes and (b) activation energies.

volume fraction of precipitation or dissolution. The effects of excess Si content on the enthalpy changes for the reactions $\mathrm{A}$ and $\mathrm{C}$ are shown in Fig. 4(a). These enthalpy changes increased with increasing Si content. The enthalpy change for the reaction A increased from 1.9 to $3.8 \mathrm{~J} / \mathrm{g}$ and that for the reaction $\mathrm{C}$ varied from 4.5 to $9.9 \mathrm{~J} / \mathrm{g}$ with increasing the excess $\mathrm{Si}$ contents from -0.26 to 0.57 at $\%$. The activation energies for the reactions were calculated by Kissinger method: ${ }^{25)}$

$$
\ln \frac{T_{\mathrm{f}}^{2}}{\Phi}=\frac{Q^{*}}{R T_{\mathrm{f}}}+\ln \frac{Q^{*}}{R k_{0}}
$$

Here, $T_{\mathrm{f}}$ is the peak temperature for a reaction, $\Phi$ is the heating rate, $R$ is the gas constant, $k_{0}$ is the pre-exponential factor and $Q^{*}$ is the activation energy of the reaction. Since the last
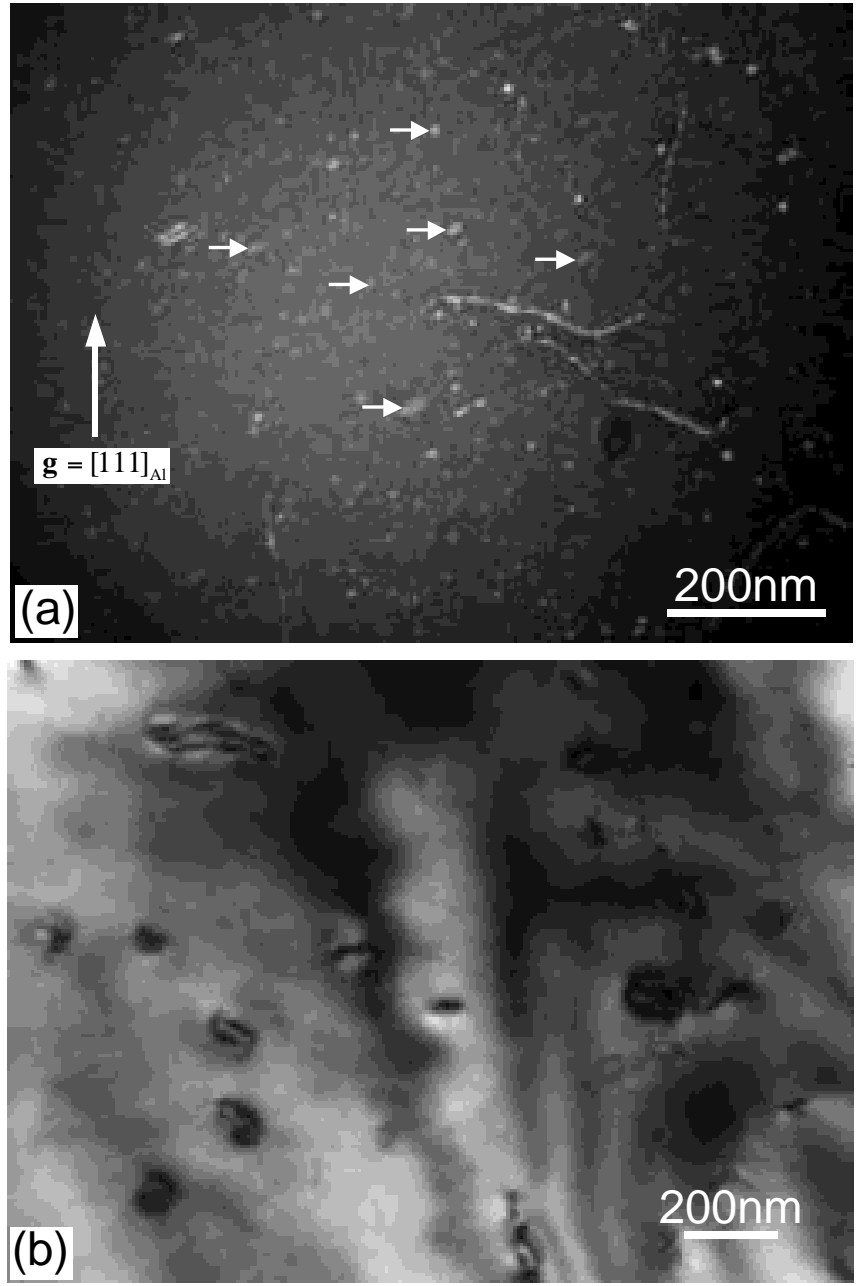

Fig. 5 Prismatic dislocation loops formed by the collapse of quenched-invacancy clusters. (a) The weak beam dark field image for the excess $\mathrm{Si}$ alloy 5 aged to $348 \mathrm{~K}$ at $10 \mathrm{~K} / \mathrm{min}$, and (b) the bright field image for the excess Mg alloy 1 aged to $390 \mathrm{~K}$ at $50 \mathrm{~K} / \mathrm{min}$.

term in the above equation can be approximated as a constant, the activation energy $Q^{*}$ can be obtained from the slope of $\ln \left(T_{\mathrm{f}}^{2} / \Phi\right)$ against $1 / T_{\mathrm{f}}$. The fraction decomposed, $Y$, can be described by Johnson-Mehl-Abrami equation ${ }^{26,27)}$ as:

$$
Y=1-\exp \left(-\beta^{n}\right)
$$

Here

$$
\beta=\int_{T_{\mathrm{i}}}^{T_{\mathrm{f}}} k_{\mathrm{r}}(T) \mathrm{d} T
$$

and

$$
k_{\mathrm{r}}=k_{0} \exp \left(-Q^{*} / R T\right) .
$$

Figure 4(b) shows that the excess Si does not affect on the activation energies for the reactions $\mathrm{A}$ and $\mathrm{C}$. The activation energies for the diffuse exothermic reaction $\mathrm{A}$ are in the range from 52.3 to $64.5 \mathrm{~kJ} / \mathrm{mol}$ but those for the sharp exothermic reaction $\mathrm{C}$ are in the ranges from 100.8 to $118.8 \mathrm{~kJ} / \mathrm{mol}$.

\subsection{TEM observations}

The TEM images of the specimens aged to the peak temperatures for the reaction A are shown in Fig. 5. Figures 5(a) and (b) are the weak beam dark field image using the $(111)_{\mathrm{Al}}$ 
reflection for the excess Si alloy 5 aged to $348 \mathrm{~K}$ at $10 \mathrm{~K} / \mathrm{min}$ and the bright field image for the excess $\mathrm{Mg}$ alloy 1 aged to $390 \mathrm{~K}$ at $50 \mathrm{~K} / \mathrm{min}$, respectively. In the excess Si specimen, many small dotlike contrasts can be seen as in Fig. 5(a) as indicated by small arrows. It is likely that these contrasts arose from the Frank-type edge dislocation loops formed by the collapse of vacancy clusters on the $\{111\}_{\mathrm{Al}}$ planes. ${ }^{28)}$ In the excess $\mathrm{Mg}$ specimen, much larger dislocation loops were observed as shown in Fig. 5(b). The difference in loop size between two specimens may arise from either the maximum heating temperature or the chemical composition. These dislocation loop contrasts were very sensitive to heating temperature, difficult to observe in the specimens aged to the peak temperature of diffuse hardening, PH1, and could never be observed in the specimens aged to the temperatures where the endothermic reaction $\mathrm{B}$ completed.

Figure 6 shows very fine needlelike precipitates formed by heating at $50 \mathrm{~K} / \mathrm{min}$ to $573 \mathrm{~K}$, the peak temperature for the reaction $\mathrm{C}$ in the excess $\mathrm{Si}$ alloy 5 . The bright field image and the selected area electron diffraction pattern are in Figs. 6(a) and (b). The reflecting zone axis was close to the $[0 \overline{3} 1]_{\mathrm{Al}}$ and very fine needles elongated in $\langle 100\rangle_{\mathrm{Al}}$ directions and dotlike contrasts can also be recognised in Fig. 6(a). These dotlike contrasts arose from the cross sections of the needles elongating into the direction normal to the foil. The diffraction
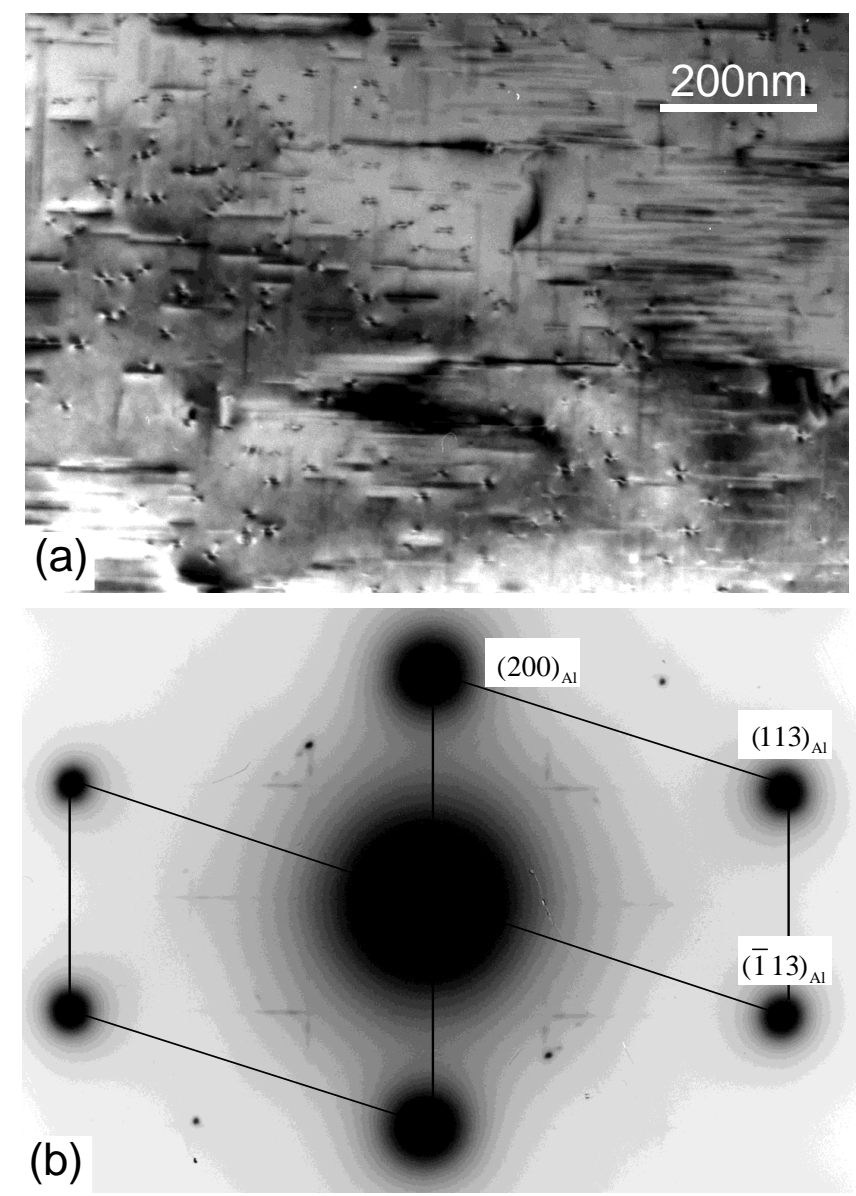

Fig. 6 Needlelike precipitates formed by heating at $50 \mathrm{~K} / \mathrm{min}$ to the peak D temperature, $573 \mathrm{~K}$, in the excess Si alloy 5. (a) The bright field image and (b) the selected area electron diffraction pattern. The reflecting zone axis was $[0 \overline{3} 1]_{\mathrm{Al}}$. spots from the needlelike precipitates were largely elongated as often reported for $\beta^{\prime \prime}$ phase, the directions of the streaks being normal to the $\langle 100\rangle_{\mathrm{Al}}$ needle directions. Although the well defined reflections from $\beta^{\prime \prime}$ needles could be obtained in the specimens isothermally aged for long time at temperatures below $523 \mathrm{~K}$, only the streaks were observed in the continuously heated specimens. This may arise from the facts that the precipitating phases change before $\beta^{\prime \prime}$ needles grow large enough to produce the well defined reflections during continuous heating.

In order to reveal the effects of chemical composition on the reaction $\mathrm{D}$, the fine structures in the excess $\mathrm{Mg}$ alloy 1 were examined first. Figure 7 shows the TEM image for the excess $\mathrm{Mg}$ alloy 1 aged to $553 \mathrm{~K}$ at $10 \mathrm{~K} / \mathrm{min}$, where the reactions $\mathrm{C}$ and $\mathrm{D}$ were overlapped. The bright field image, the selected area electron diffraction pattern with its analysis are in Figs. 7(a), and (b), respectively. The reflecting zone axis is parallel to the $[001]_{\mathrm{Al}}$ matrix direction. Fine particles with the average size of $10-20 \mathrm{~nm}$ can be recognised as well as $\beta^{\prime \prime}$ needles. The diffraction pattern and its analysis indicate that the fine particles are of $\beta$-phase relating to the $\mathrm{Al}$ matrix with the cube-cube orientation relationship, i.e., $(100)_{\beta} \|(100)_{\mathrm{Al}}$, $(010)_{\beta} \|(010)_{\mathrm{Al}}$, as reported previously. ${ }^{7,9,24)}$ In the specimen aged to $635 \mathrm{~K}$ at $50 \mathrm{~K} / \mathrm{min}, \beta^{\prime \prime}$ needles disappeared almost completely and only cuboid $\beta$ particles were recognised.

In the case of the quasi-binary alloy 2 aged at $50 \mathrm{~K} / \mathrm{min}$
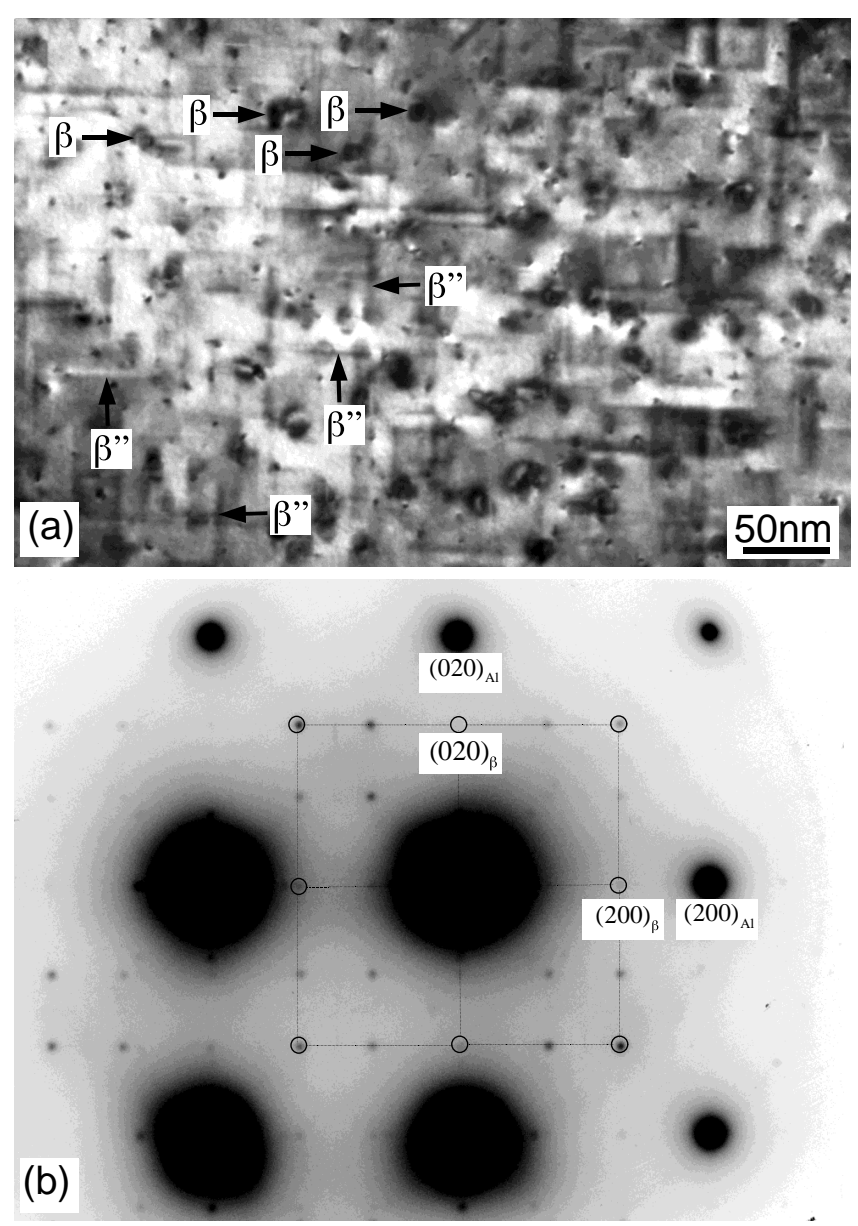

Fig. 7 Fine cuboid particles and the $\beta^{\prime \prime}$ needles formed by heating at $10 \mathrm{~K} / \mathrm{min}$ to $553 \mathrm{~K}$ in the excess $\mathrm{Mg}$ alloy 1 . (a) Bright field image and (b) the selected area electron diffraction pattern with its analysis. 


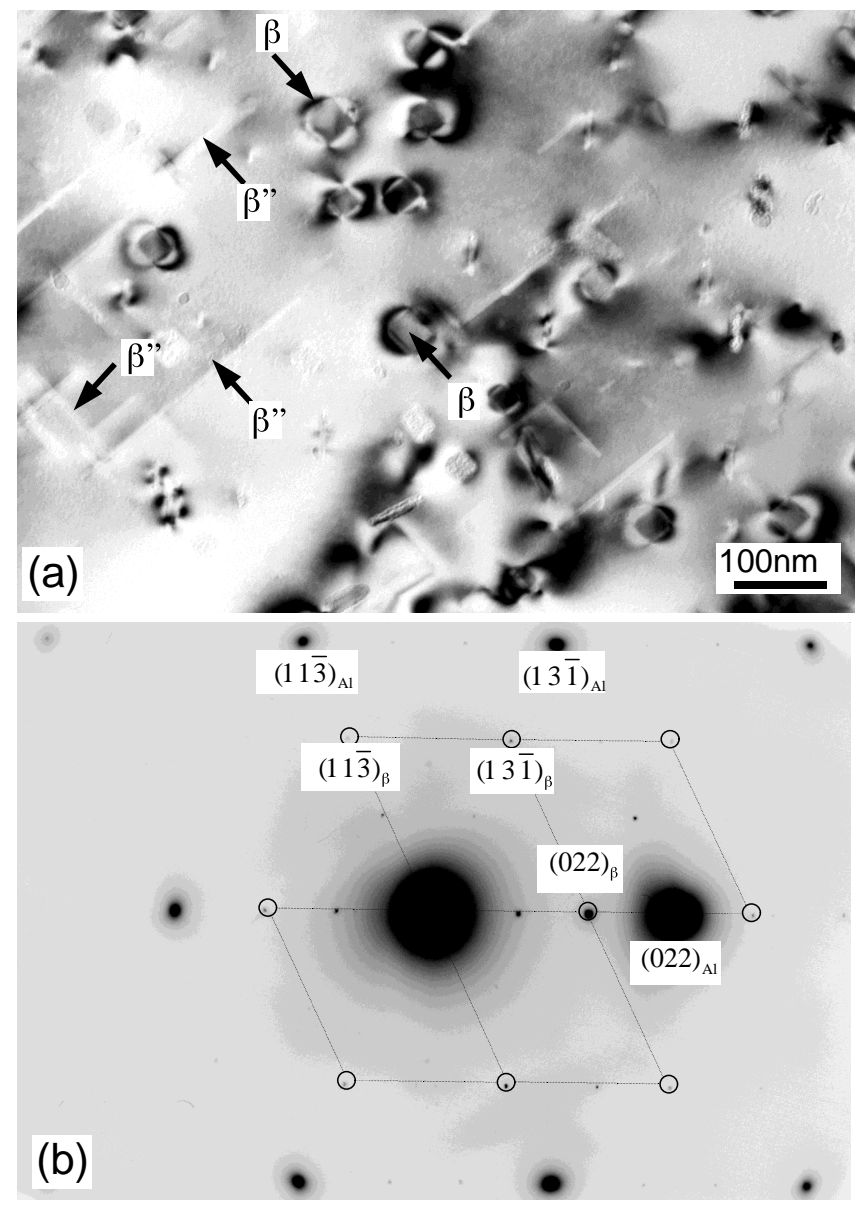

Fig. 8 Cuboid $\beta$ particles and $\beta^{\prime \prime}$ needles formed by heating at $50 \mathrm{~K} / \mathrm{min}$ to $635 \mathrm{~K}$ in the quasi-binary alloy 2. (a) Bright field image and (b) the selected area electron diffraction pattern with its analysis.

to $635 \mathrm{~K}$ where the reaction $\mathrm{D}$ has nearly completed, cuboid $\beta$ particles much coarser than those in the excess $\mathrm{Mg}$ alloy were observed as well as fine $\beta^{\prime \prime}$ needles. The number of the $\beta$ particles, however, decreased significantly in comparison with that in the excess $\mathrm{Mg}$ alloy. Figures 8(a) and (b) are the bright field image in the $[\overline{4} 1 \overline{1}]_{\mathrm{Al}}$ zone axis and the selected area electron diffraction pattern with its analysis. The cuboid particles were confirmed to be $\beta$ phase as shown in Fig. 8(b). The surfaces of the cubes appeared to be parallel to the $\{100\}_{\mathrm{Al}}$ matrix planes as reported previously. ${ }^{7,9,24)}$ Very fine needles lying parallel to $\langle 100\rangle_{\mathrm{Al}}$ directions are probably of $\beta^{\prime \prime}$ phase although the diffraction pattern from them could not be obtained due to small density of the precipitates in this area. In a different area of the same specimen, however, a much coarse rodlike precipitate with the average diameter of $15 \mathrm{~nm}$ was observed occasionally as indicated by an arrow in Fig. 9(a). The diffraction pattern and its analysis in Fig. 9(b) indicates that the rodlike precipitate is of hexagonal $\beta^{\prime}$ phase determined by Jacobs. ${ }^{2)}$ The orientation relationship between the $\beta^{\prime}$ rod and the matrix can be expressed as:

$$
\begin{aligned}
& (130)_{\mathrm{Al}}\left\|(1 \overline{1} \overline{2} 0)_{\beta^{\prime}},(\overline{3} 10)_{\mathrm{Al}}\right\|(1 \overline{1} 00)_{\beta^{\prime}},[001]_{\mathrm{Al}} \|[0001]_{\beta^{\prime}} \\
& \ldots \text { growth direction }
\end{aligned}
$$

This relationship is close to that of the middle range type ob-

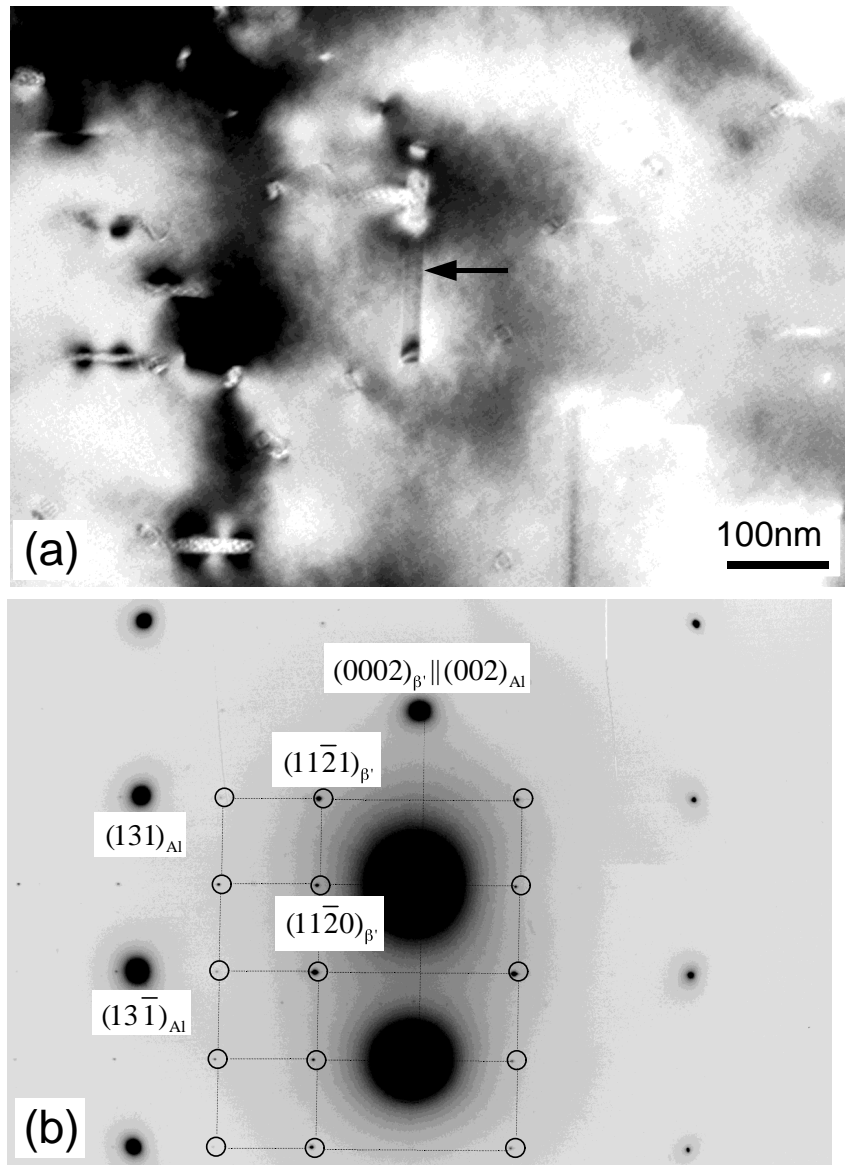

Fig. $9 \beta^{\prime}$ rod formed by heating at $50 \mathrm{~K} / \mathrm{min}$ to $635 \mathrm{~K}$ in the quasi-binary alloy 2. An arrow indicates a $\beta^{\prime}$ rod. (a) Bright field image and (b) the selected area electron diffraction pattern with its analysis.

tained by Matsuda et $a .^{29)}$ as:

$$
\begin{gathered}
(100)_{\mathrm{Al}} \text { about } 20^{\circ} \text { from }(11 \overline{2} 0)_{\beta^{\prime}},[001]_{\mathrm{Al}} \|[0001]_{\beta^{\prime}} \\
\ldots \text { growth direction }
\end{gathered}
$$

In the excess $\mathrm{Si}$ alloy 5 aged continuously to $635 \mathrm{~K}$ at $50 \mathrm{~K} / \mathrm{min}$, both cuboid and platelike $\beta$ particles were also detected occasionally. Platelike $\beta$ particles were significantly larger than cuboid particles, i.e., $50-150 \mathrm{~nm}$ in edge length and $7-15 \mathrm{~nm}$ thick, as can be seen in Fig. 10(a). The density of them, however, was very low. The $\beta$-plate/Al orientation relationship can be determined from the diffraction pattern (Fig. 10(b)) as:

$$
\begin{aligned}
& (021)_{\beta}\left\|(013)_{\mathrm{Al}},(0 \overline{1} 2)_{\beta}\right\|(0 \overline{3} 1)_{\mathrm{Al}},(100)_{\beta} \|(100)_{\mathrm{Al}} \\
& \text { } \ldots \text { habit plane }
\end{aligned}
$$

This relationship is rotated $8^{\circ}$ about the $[100]_{\beta} \|[100]_{\mathrm{Al}}$ axis from the cube-cube relationship, i.e., the separation angle between $(021)_{\beta}$ and $(013)_{\mathrm{Al}}$ is about $8^{\circ}$. Although this rotation from the cube-cube relationship is relatively small, it may not be an experimental error. This is because $\beta$ particle would have taken a cuboid morphology if the isotropic cube-cube relation held between it and the matrix. In the same specimen, $\beta^{\prime}$ and Type-B rods were frequently recognised. The bright field image of a $\beta^{\prime}$ rod indicated by an arrow and the selected area electron diffraction pattern with its analysis are in Figs. 11(a) and (b), respectively. The orientation relationship be- 

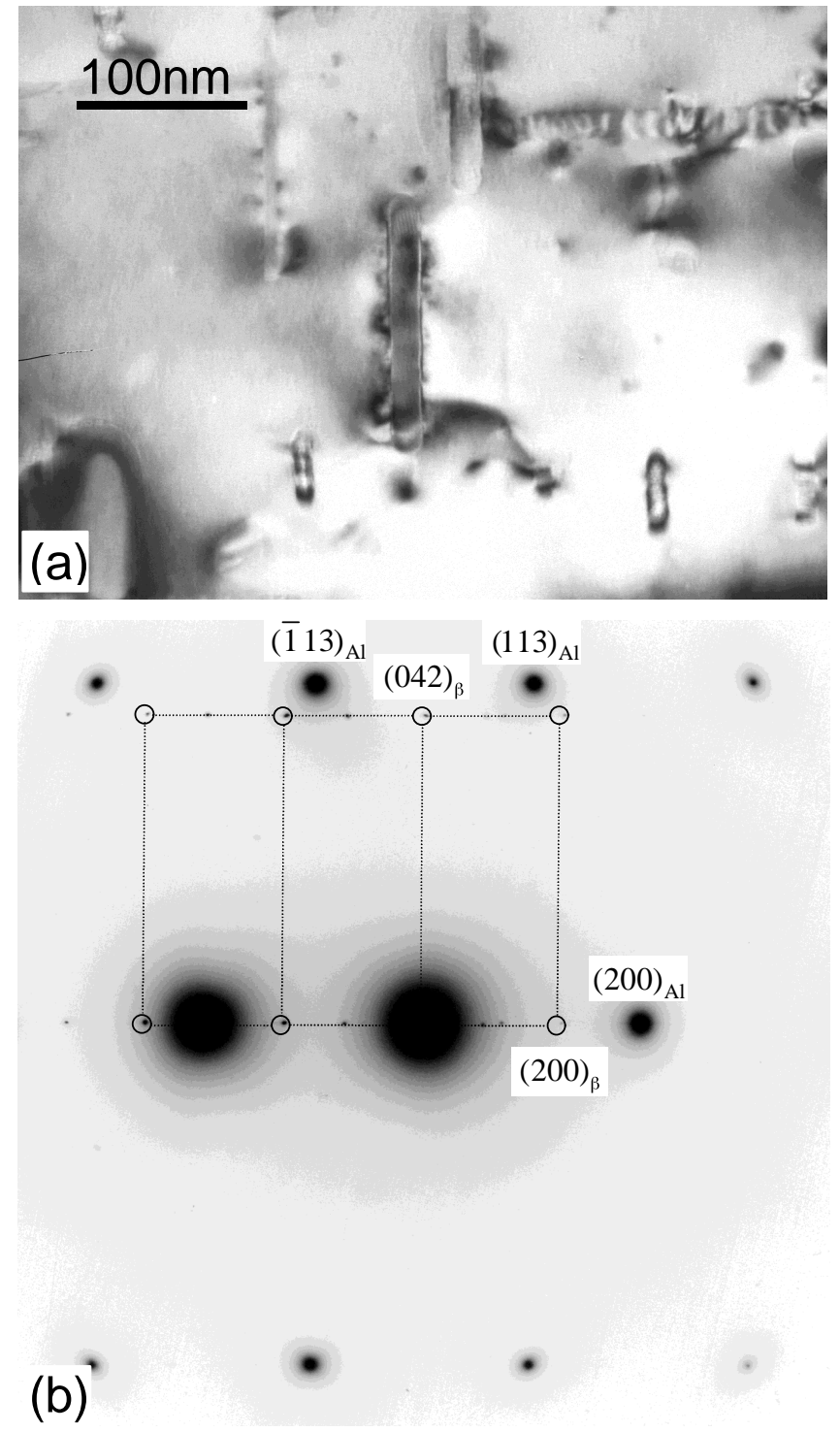

Fig. $10 \beta$ particles formed by heating to $635 \mathrm{~K}$ at $50 \mathrm{~K} / \mathrm{min}$ in the excess Si alloy 5. (a) The bright field image and (b) the selected area electron diffraction pattern with its analysis.

tween the $\beta^{\prime}$ rod and the matrix can be expressed by the same variant of the relationship in Fig. 9. Figure 12 illustrates the region where both $\beta^{\prime}$ and Type-B rods were observed simultaneously. The bright field image and the selected area electron diffraction pattern are in Figs. 12(a) and (b), respectively. The zone axis of this image is parallel to the $[100]_{\mathrm{Al}}$ direction and three equivalent variants of the $\beta^{\prime} / \mathrm{Al}$ orientation relationship were recognised. The $\beta^{\prime} / \mathrm{Al}$ orientation relationship for the $\beta^{\prime}$ rods shown as " $\beta^{\prime} 1$ " can be expressed as:

$$
\begin{gathered}
(\overline{1} 100)_{\beta^{\prime}}\left\|(100)_{\mathrm{Al}},(\overline{1} \overline{1} 20)_{\beta^{\prime}}\right\|(010)_{\mathrm{Al}},[0001]_{\beta^{\prime}} \|[001]_{\mathrm{Al}} \\
\ldots \text { growth direction } .
\end{gathered}
$$

This is in good agreement with the zero-type relationship obtained by Matsuda et al. ${ }^{29)}$ In addition to $\beta^{\prime}$ rods, rather thin and wavy rods were observed in Fig. 12(a) and they can be indexed as Type-B precipitates determined by Matsuda $e t$ $a l .{ }^{10-13)}$ as shown in Fig. 12(b). The orientation relationship
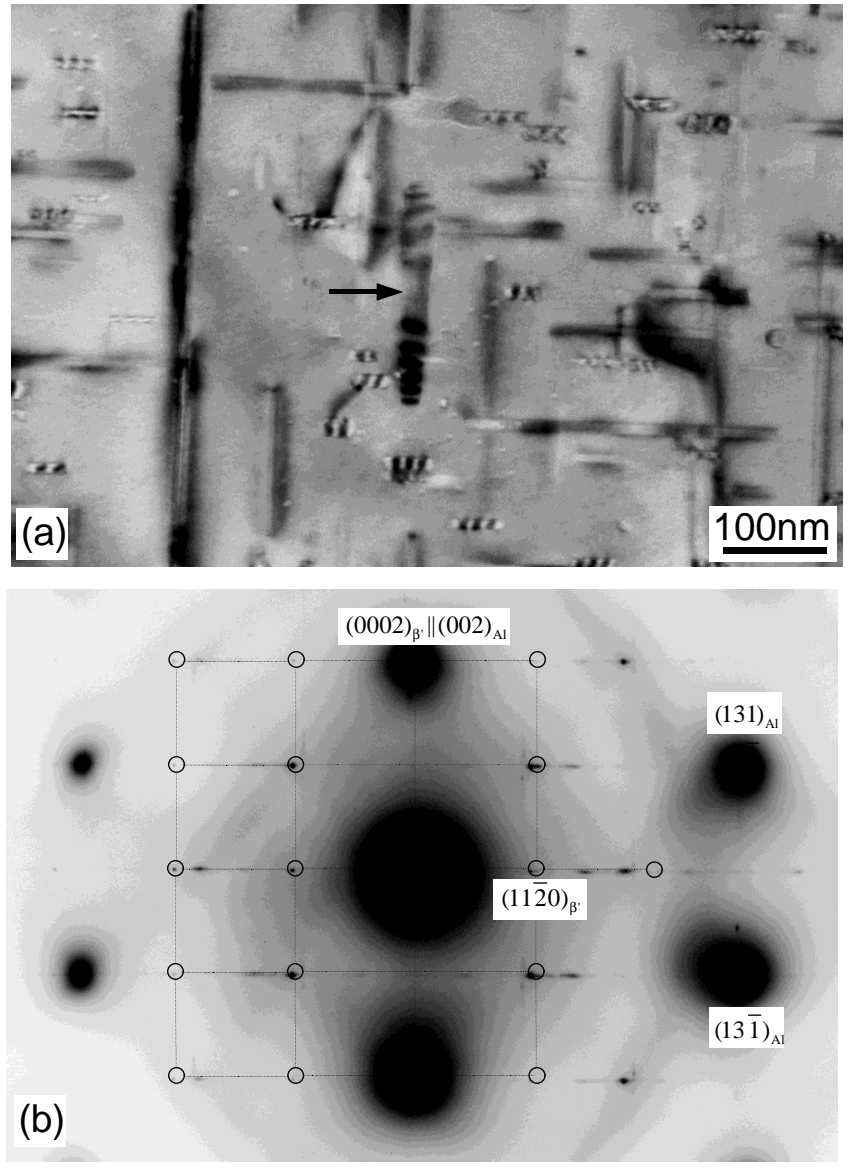

Fig. 11 Precipitation of $\beta^{\prime}$ rods in the excess Si alloy 5 aged at $50 \mathrm{~K} / \mathrm{min}$ to $635 \mathrm{~K}$. (a) Bright field image and (b) the selected area electron diffraction pattern with its analysis.

between Type-B rods and the matrix can be expressed as:

$$
\begin{gathered}
(100)_{\mathrm{B}}\left\|(30 \overline{1})_{\mathrm{Al}},(010)_{\mathrm{B}}\right\|(\overline{1} 0 \overline{3})_{\mathrm{Al}},[001]_{\mathrm{B}} \|[010]_{\mathrm{Al}} \\
\cdots \text { growth direction }
\end{gathered}
$$

and is in keeping with that obtained also by Matsuda et al. ${ }^{12)}$ In the same specimen, the dispersion of Si particles was also recognised. An example is shown in Fig. 13. The bright field image and the selected area electron diffraction pattern are in Figs. 13(a) and (b), respectively. No specific orientation relationship between the $\mathrm{Si}$ particle and the matrix was obtained but the edges of the particle were parallel to $\langle 110\rangle_{\mathrm{Si}}$ directions.

By ageing the excess Si alloy to $673 \mathrm{~K}$, Type-B rods were frequently observed in addition to $\beta^{\prime}$ rods, $\beta$ and Si particles. Figure 14 is an example of it. Two equivalent sets of mutually orthogonal Type-B rods lay parallel to the $\langle 100\rangle_{\mathrm{Al}}$ directions (Fig. 14(a)). The diffraction pattern, Fig. 14(b), indicates that the relationships between the Type-B rods and the matrix are in good agreement with that obtained by Matsuda et al. ${ }^{12)}$ as described above. This pattern could never be indexed as either $\beta^{\prime}$ or Type-A precipitate. It should be noted that Type A and $C$ precipitates which have been observed in the isothermally aged excess Si alloys, however, could not be recognised in the specimens continuously heated. 

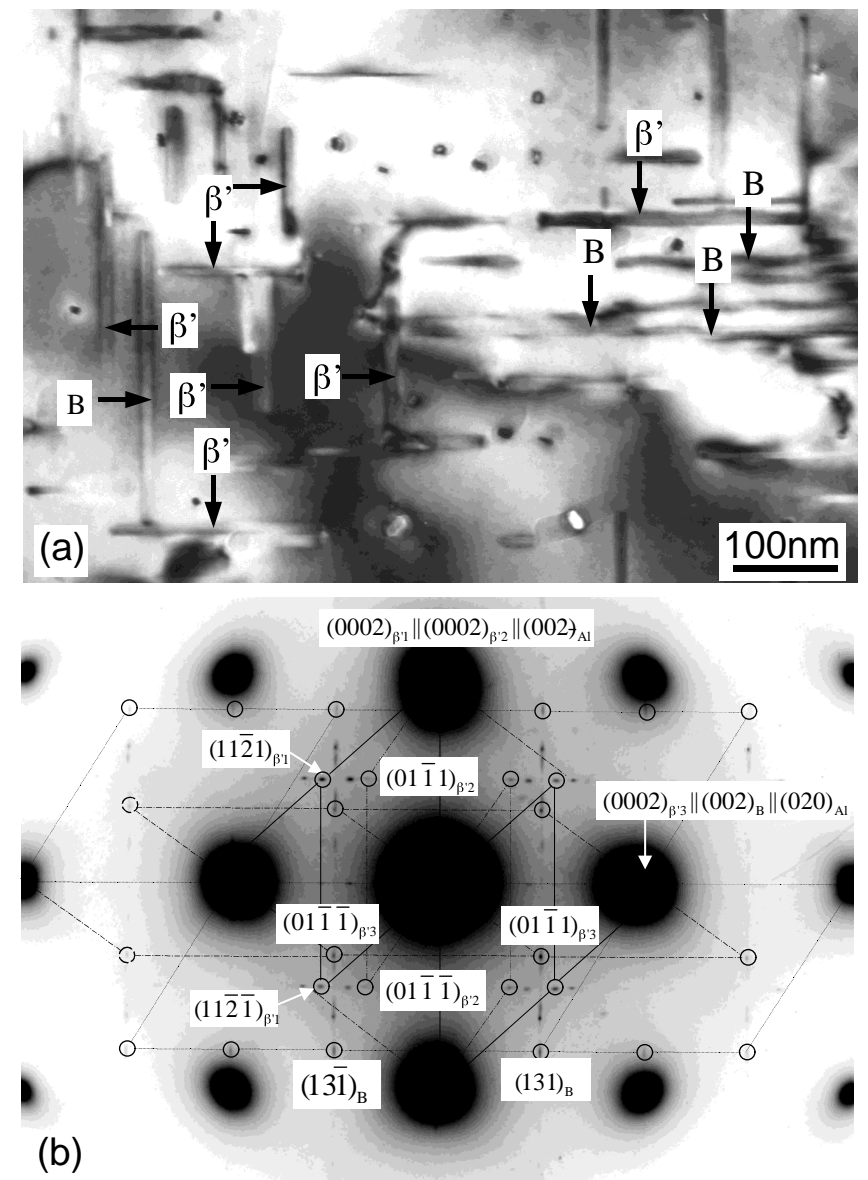

Fig. 12 Precipitation of $\beta^{\prime}$ and Type-B rods in the excess Si alloy 5 aged at $50 \mathrm{~K} / \mathrm{min}$ to $635 \mathrm{~K}$. (a) Bright field image and (b) the selected area electron diffraction pattern with its analysis.

\section{Discussion}

In order to clarify the ageing processes during continuous heating, three points described below should be noted.

(1) The first slight hardening peak (PH1) does not coincide with the exothermic peak A and deviates about 50-80 K to one another.

(2) The peak height ratio of the reaction $\mathrm{D}$ to the reaction $\mathrm{C}$ decreases with increasing excess $\mathrm{Si}$ content, and at this ageing stage cuboid $\beta$ particles precipitate predominantly in excess $\mathrm{Mg}$ and low excess $\mathrm{Si}$ alloys.

(3) In the excess $\mathrm{Mg}$ specimen heated continuously to $635 \mathrm{~K}$ at $50 \mathrm{~K} / \mathrm{min}$, only the dispersion of cuboid $\beta$ particles is observed. In the quasi-binary specimen of the same ageing condition, $\beta^{\prime}$ rods precipitate in addition to $\beta^{\prime \prime}$ and $\beta$ particles. In the excess Si specimen, the precipitation of Type B rods was also observed. The precipitation of Type $\mathrm{A}$ and $\mathrm{C}$ rods, however, could not be recognised in the present continuous heating experiments.

The first exothermic reaction A has been interpreted as the formation of solute atom clusters so far. ${ }^{1,4,31)}$ It should, however, be pointed out that this temperature is much lower than the broad hardening peak (PH1) which is thought to be the solute atom cluster formation. In the specimens aged to the temperature where the reaction A was detected, however, the contrasts arising probably from prismatic dislocation loops
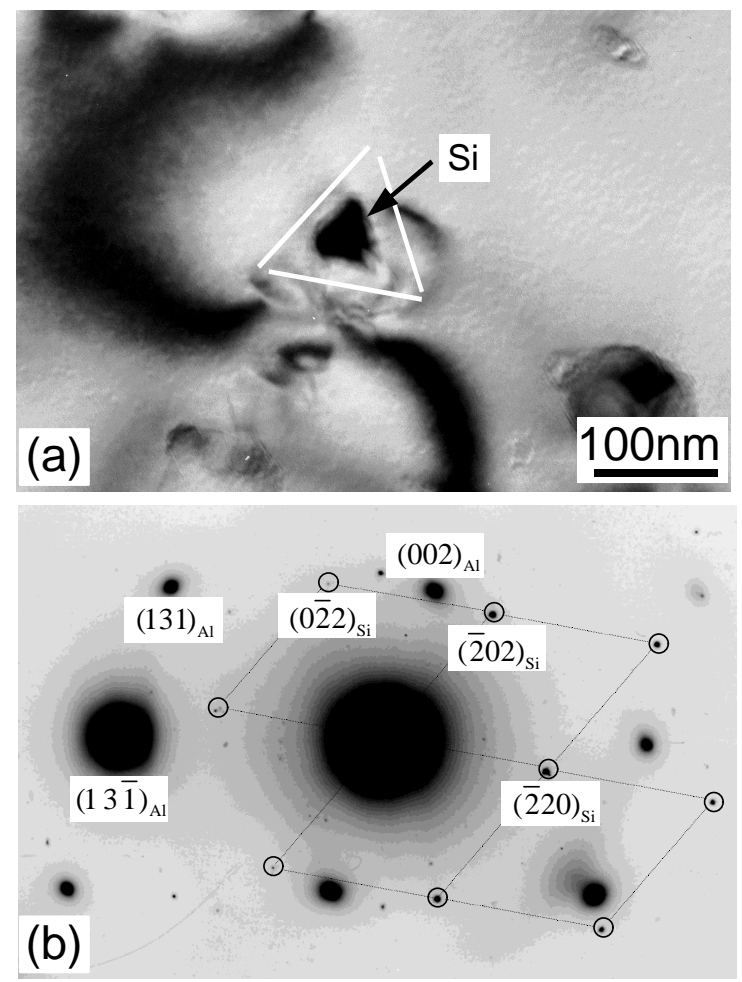

Fig. 13 Silicon particle formed by heating to $635 \mathrm{~K}$ at $50 \mathrm{~K} / \mathrm{min}$ in the excess Si alloy 5 . White lines indicate the traces of $\langle 110\rangle_{\mathrm{Si}}$ directions. (a) The bright field image and (b) the selected area electron diffraction pattern with its analysis.

were observed as shown in Fig. 5. It is also likely that the excess vacancies are dissipated by forming vacancy clusters as well as by migrating to some sinks such as grain boundaries. Suzuki et al. $^{23)}$ reported that such dislocation loops are difficult to observe in the $\mathrm{Al}-\mathrm{Mg}-\mathrm{Si}$ alloys aged at $448 \mathrm{~K}$ for $10 \mathrm{~min}$. This may arise from the facts that the loops can be observed in quite narrow temperature range during continuous heating and also those in the excess Si alloys are very small in size. The subsequent migration of solute atoms to the prismatic dislocation loops will eliminate the loops, leading to the formation of solute atom clusters. These solute atom clusters are also difficult to observe by TEM as reported by Suzuki et $a l .{ }^{32)}$ In fact, according to our unpublished work, the isothermal ageing at $448 \mathrm{~K}$ for $10 \mathrm{~min}$ corresponds to the initial stage of $\beta^{\prime \prime}$ precipitation where such loops can never be observed. The exothermic heat and the activation energy for the reaction A are in the ranges from 1.9 to $3.8 \mathrm{~J} / \mathrm{g}$ and 52.3 to $64.5 \mathrm{~kJ} / \mathrm{mol}$, respectively, as shown in Fig. 4. In 6061 alloys, Dutta et $a l{ }^{4)}$ reported that this activation energy is $33.1 \mathrm{~kJ} / \mathrm{mol}$, but Doan et $_{\text {al. }}{ }^{33)}$ determined the enthalpy change and the activation energy as $1.3 \mathrm{~J} / \mathrm{g}$ and $79 \mathrm{~kJ} / \mathrm{mol}$, respectively. The activation energies obtained in the present alloys are, therefore, inbetween of the values described above. ${ }^{4,33)}$ These values are much smaller than those for the bulk diffusions of $\mathrm{Al}, \mathrm{Si}$ and $\mathrm{Mg}$ atoms in $\mathrm{Al}$ matrix, i.e., 142, 124 and $131 \mathrm{~kJ} / \mathrm{mol}$, respectively. ${ }^{34)}$ On the other hand, since the specimens quenched from the solutionised temperature involve quite dense supersaturated quenched-in-vacancies, the activation energy will comprise mainly that of vacancy migration. In fact, the activation energies reported for vacancy migration in $\mathrm{Al}$ matrix are in the range from 0.4 to $0.75 \mathrm{eV},{ }^{35)}$ i.e., from 39 to $72 \mathrm{~kJ} / \mathrm{mol}$ 


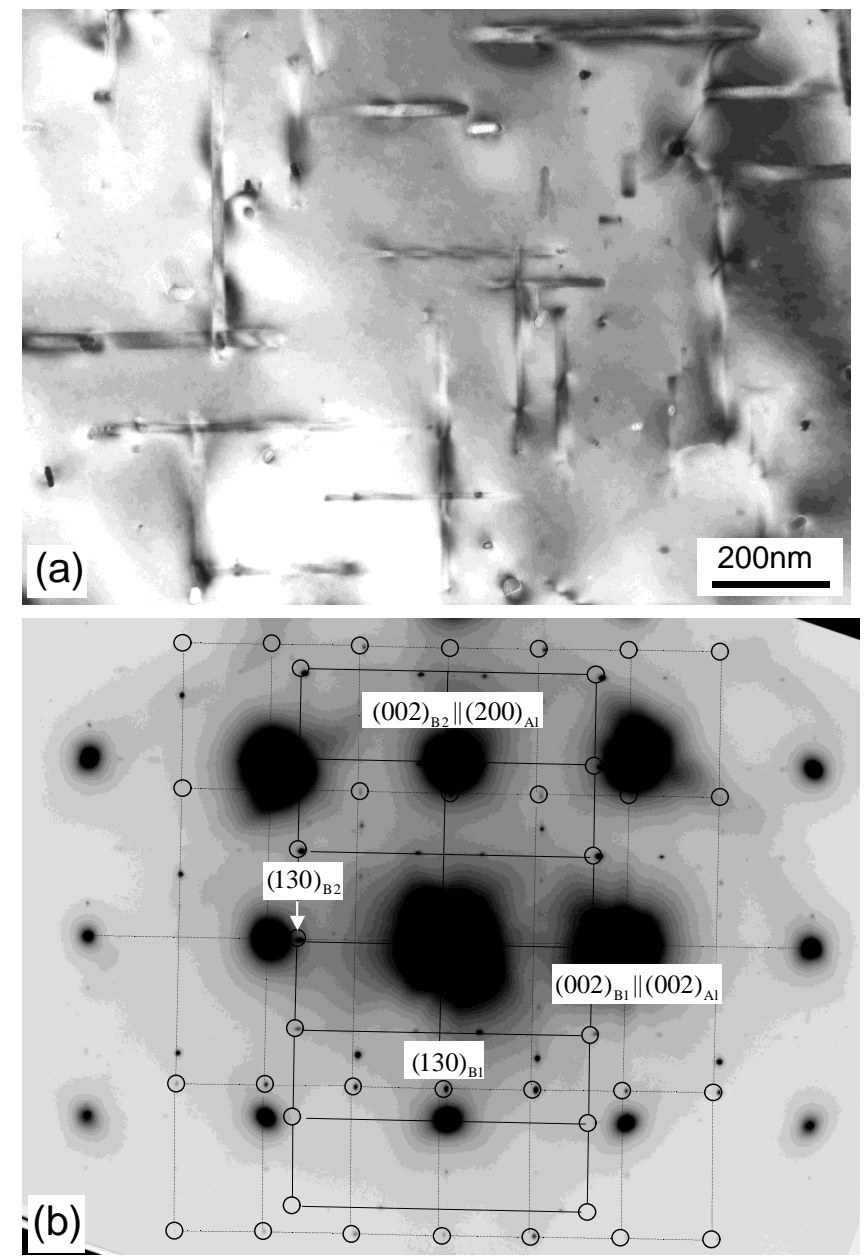

Fig. 14 Type-B precipitates formed in the excess $\mathrm{Si}$ alloy 5 aged at $50 \mathrm{~K} / \mathrm{min}$ to $673 \mathrm{~K}$. (a) Bright field image and (b) the selected area electron diffraction pattern with its analysis.

and are in keeping with the activation energy obtained in the present experiment. The exothermic heat due to the reaction $\mathrm{A}$ is in the ranges from 1.9 to $3.8 \mathrm{~J} / \mathrm{g}$ as described above. If the reaction $\mathrm{A}$ arises from the annihilation of vacancies by both the collapse of vacancy clusters and the migration to various vacancy sinks, the heat will be in the range from 2.6 to $26 \mathrm{~J} / \mathrm{g}$ corresponding to the densities of dissipated vacancies in the range from 0.01 to $0.1 \mathrm{~mol}$. Of course, vacancies will not be fully dissipated and the formation energy of dislocation loops should also be taken in account, the latter being about $20 \%$ in the case of the loops of $10 \mathrm{~nm}$ in diameter. Considering these requirements, the heat obtained is in the reasonable range for the interpretation as the dissipation of vacancies by migrating to the sinks such as grain boundaries and forming dislocation loops. It should also be noted that the present DSC results do not eliminate the possibility of solute atom cluster formation because solute atom clusters are also formed by the vacancy migration. However, in order to explain the temperature separation between DSC-A and PH1 as well as TEM results, it will be reasonable to interpret the DSC-A as the annihilation of vacancies by forming prismatic dislocation loops and also migrating to the sinks such as grain boundaries.

The broad increase in hardness at temperatures $50-80 \mathrm{~K}$ above the reaction A, (PH1), is probably due to the formation of solute atom clusters. Since the peak height in hard- ness increases with increasing excess Si content as can be seen in Fig. 1, it is likely that the solute atom clusters comprise mainly $\mathrm{Si}$ atoms. The possibility of $\mathrm{Mg}$ co-clustering, which was confirmed by Murayama and $\mathrm{Hono}^{36)}$ by means of AP-FIM, of course, cannot be eliminated. The assumption that $\mathrm{PH} 1$ corresponds to the solute atom cluster formation is also supported by the properties of the endothermic reaction B. That is, if PH1 arises from the formation of solute atom clusters, the reaction $\mathrm{B}$ will be due to the dissolution of them. In fact, the absorbed heat for the reaction $B$ increases with increasing excess Si content as shown in Fig. 2 but the activation energy for it is independent of the excess Si content, about $165 \mathrm{~kJ} / \mathrm{mol}$, and is rather close to those for solute atom diffusions, as can be seen in Fig. 4(b). This result suggests that the formation and dissolution of solute atom clusters occur in these processes.

Reaction $\mathrm{C}$ is associated with the precipitation of $\beta^{\prime \prime}$ needles as reported in various literatures. The enthalpy change of the reaction $\mathrm{C}$ increases from 5 to $10 \mathrm{~J} / \mathrm{g}$ with increasing excess $\mathrm{Si}$ from -0.26 to 0.57 at $\%$. These values are very close to those obtained previously in a 6061 alloy, ${ }^{33)}$ i.e., from 4.83 to $6.81 \mathrm{~J} / \mathrm{g}$. The activation energies for these reactions, however, are in the range from 100.8 to $118.8 \mathrm{~kJ} / \mathrm{mol}$ and are significantly smaller than those for the solute atom diffusion in $\mathrm{Al}$ matrix. ${ }^{34)}$ This may be due to the interaction between the reactions $\mathrm{C}$ and $\mathrm{D}$. If the reaction $\mathrm{D}$ starts before the reaction $\mathrm{C}$ completes, the higher temperature side of the reaction $\mathrm{C}$ will be replaced by the reaction $\mathrm{D}$. Thus, the higher temperature side of the true peak $\mathrm{C}$ will be lost, consequently the apparent peak temperature being lowered. Since the reaction $\mathrm{D}$ at a slow heating rate starts prior to the completion of the reaction $\mathrm{C}$ much faster than that at a rapid heating rate, the apparent peak $\mathrm{C}$ in slow heating will displace to lower temperatures, resulting in the low activation energy as expected from the Kissinger equation. ${ }^{24)}$ This may explain the low activation energy of this reaction.

On the other hand, the next reaction $\mathrm{D}$ has been interpreted as the growth process of $\beta^{\prime \prime}$ needles into $\beta^{\prime}$ rods so far. ${ }^{4,5)}$ It should, however, be emphasised that most of such conclusions $^{4,5)}$ are based on the fact that $\beta^{\prime \prime}$ needles transform eventually into $\beta^{\prime}$ rods during the isothermal ageing at temperatures lower than the reaction D peak in continuous heating. If this conclusion were true, the peak height ratio in Fig. 3, $h_{\mathrm{D}} / h_{\mathrm{C}}$, would have increased with increasing excess Si content because the amounts of rodlike precipitates increase with increasing excess $\mathrm{Si}$ content as described in a previous paper. ${ }^{24)}$ However, $h_{\mathrm{D}} / h_{\mathrm{C}}$ decreases drastically with increasing excess $\mathrm{Si}$ content above $0.2 \%$. It should also be noted that cuboid $\beta-\mathrm{Mg}_{2} \mathrm{Si}$ particles precipitate densely in the excess $\mathrm{Mg}$ and the quasi-binary alloys aged to the temperature where the reaction D occurs as in Figs. 7 and 8. The number of $\beta$ $\mathrm{Mg}_{2} \mathrm{Si}$ particles decreases with increasing excess Si content in accordance with the excess Si content dependency of $h_{\mathrm{D}} / h_{\mathrm{C}}$. Thus, the reaction $\mathrm{D}$ arises probably from the precipitation of $\beta-\mathrm{Mg}_{2} \mathrm{Si}$ particles. Suzuki et al., ${ }^{38)}$ however, confirmed by the in-situ TEM observation that cuboid $\beta$ particles nucleate at $\beta^{\prime}$ rods and grow with consuming the rods at temperatures from $481-523 \mathrm{~K}$ after the isothermal ageing at $523 \mathrm{~K}$ for $10 \mathrm{~min} .{ }^{38)}$ Unfortunately in their study the diffraction pattern showing that the rodlike precipitates were really of $\beta^{\prime}$ 
phase were not shown. According to our unpublished work, many $\beta^{\prime \prime}$ needles were recognised in this ageing condition although the average size of them was much larger than those initially formed, the crystal structure and the $\beta^{\prime \prime} /$ matrix orientation relationship being in keeping with those determined by Andersen. ${ }^{18)}$ Thus, it can also be interpreted that cuboid $\beta$ particles nucleate at the interfaces of $\beta^{\prime \prime}$ needles. This interpretation is supported by the fact that the reaction $\mathrm{D}$ follows immediately after the reaction $\mathrm{C}$. The reason that the formation of $\beta^{\prime}$ rods did not produce a well defined peaks in DSC curves may arise from the small exothermic heat for their formation. Similar effects are also observed in the case of the precipitation of Type-B rods and Si particles.

In the continuously heated excess $\mathrm{Mg}$ specimens, rodlike precipitates could not be detected in all the temperature range examined. Matsuda et al. ${ }^{37)}$ however, observed $\beta^{\prime}$ rods forming in the excess $\mathrm{Mg}$ alloy aged isothermally at $473 \mathrm{~K}$ for long time. In the case of isothermal ageing at lower temperatures where the atomic diffusion is slow, the precipitates with the atomic structure similar to that of the matrix will preferentially form at least in the early stages of ageing. On the other hand, in the specimens continuously heated to higher temperatures, more stable phases will precipitate even if the structures of them are significantly different from that of the matrix. Thus, the precipitation sequence in continuous heating will largely deviate from that in isothermal ageing.

In the quasi-binary and the excess $\mathrm{Si}$ alloys aged to temperatures above $635 \mathrm{~K}$ at $50 \mathrm{~K} / \mathrm{min}$, rodlike precipitates are recognised. These rods in the quasi-binary alloy are $\beta^{\prime}$ phase but in the excess Si alloys both $\beta^{\prime}$ and Type-B rods form. Coarse Type-A rods have been observed in the excess Si alloys isothermally aged. ${ }^{13)}$ In the present continuously heating experiments, however, both Type-A and -C rods could not be detected. This may also arise from the difference in the precipitation kinetics described above.

Although TEM results have not been shown at present, the final precipitation reaction $\mathrm{E}$ and the following large endothermic reaction $\mathrm{F}$ in Fig. 2 are the formation of stable $\beta$ $\mathrm{Mg}_{2} \mathrm{Si}$ plates and the dissolution of them in the matrix, respectively, as reported in various literatures.

\section{Conclusions}

The precipitation behaviours during continuous heating in the $\mathrm{Al}-\mathrm{Mg}-\mathrm{Si}$ alloys with excess $\mathrm{Mg}$ and $\mathrm{Si}$ contents have been investigated by means of Vickers hardness measurements, DSC and TEM. The results obtained are as follows.

(1) The precipitation sequence during continuous heating may be summarised as: vacancy annihilation by both forming prismatic dislocation loops and migrating to various sinks $\rightarrow$ solute atom cluster formation $\rightarrow$ dissolution of solute atom clusters $\rightarrow$ needle-shaped $\beta^{\prime \prime}$ precipitation $\rightarrow$ precipitation of fine cuboid $\beta-\mathrm{Mg}_{2} \mathrm{Si}$ particles $\rightarrow$ precipitation of $\beta^{\prime}$ rods in the quasi-binary alloy (in the excess $\mathrm{Si}$ alloys, the precipitation of $\beta^{\prime}$, Type-B rods Si particles) $\rightarrow$ precipitation of $\beta$ $\mathrm{Mg}_{2}$ Si plates $\rightarrow$ dissolution of them into the matrix.

(2) The first exothermic reaction A occurring at the lowest temperatures arises probably from the vacancy annihilation by the collapse of vacancy clusters and the migration to sinks such as grain boundaries. The prismatic dislocation loops formed by the collapse of vacancy clusters are observed.

(3) The broad hardening (PH1) following the reaction A increases with increasing excess $\mathrm{Si}$ content. It is likely that this hardening is due to the formation of solute atom clusters.

(4) The sharp and large exothermic reaction $\mathrm{C}$ inducing large hardening corresponds to the precipitation of $\beta^{\prime \prime}$ needles. Increasing excess Si content accelerates this reaction.

(5) The reaction $\mathrm{E}$ arises probably from the precipitation of $\beta-\mathrm{Mg}_{2} \mathrm{Si}$ particles. In the excess $\mathrm{Mg}$ and the quasi-binary alloys, cuboid particles showing $\beta$ - $\mathrm{Mg}_{2} \mathrm{Si}$ structure can be clearly observed at temperatures around this reaction but the increase of excess $\mathrm{Si}$ content results in the decrease of their density.

(6) In the quasi-binary alloy $\beta^{\prime}$ rods precipitate following the formation of cuboid $\beta$ particles, but in the excess $\mathrm{Si}$ alloys both $\beta^{\prime}$ and Type-B rods form.

\section{Acknowledgements}

Y. O. and K. N. would like to express sincere thanks to the Ministry of Education and Science for providing the Research Grant-in-Aids for the promotion of this research. L. C. D. would like to thank The Rotary Club for providing the scholarship for this research.

\section{REFERENCES}

1) G. Thomas: J. Inst. Metals. 90 (1961-2) 57-63.

2) M. H. Jacobs: Philos. Mag. 26 (1972) 1-13.

3) P. Barczy and F. Trante: Scand. J. Metals 4 (1975) 284-292.

4) I. Dutta and S. M. Allen: J. Mater. Sci. Lett. 10 (1991) 323-326.

5) I. Dutta, S. M. Allen and J. L. Hafley: Metall. Trans. A 22A (1991) 2553-2563.

6) G. A. Edwards, K. S. Tiller, G. L. Dunlop and M. J. Couper: Acta Mater. 46 (1998) 3893-3904.

7) M. Kanno, H. Suzuki and Y. Shiraishi: J. Japan Inst. Metals 43 (1979) 81-86.

8) H. Suzuki, M. Kanno and G. Itoh: J. Japan Inst. Light Metals 32 (1982) 290-293.

9) H. Wesrengen and N. Ryum: Z. Metalllde. 70 (1979) 528-535.

10) K. Matsuda, S. Ikeno, T. Sato and A. Kamio: Scr. Mater. 32 (1995) 1175-1180.

11) K. Matsuda, S. Ikeno, T. Sato and A. Kamio: Scr. Mater. 34 (1996) 1797-1802.

12) K. Matsuda, T. Naoi, K. Fujii, Y. Uetani, T. Sato, A. Kamio and S. Ikeno: Mater. Sci. Eng. A262 (1999) 232-237.

13) K. Matsuda, Y. Sakaguchi, Y. Miyata, Y. Uetani, T. Sato, A. Kamio and S. Ikeno: J. Mater. Sci. 35 (2000) 179-189.

14) G. A. Edwards, K. Stiller, G. L. Dunlop and M. J. Couper: Mater. Sci. Forum. 713 (1996) 217-222.

15) T. V. Shchegoleva: Phys. Met. Metallogr. 25 (1968) 56-59.

16) R. P. Wahi and M. von Heimendahl: Phys. Status Solidi (a) 24 (1974) 607-612.

17) J. P. Lynch, L. M. Brown and W. H. Jacobs: Acta Metall. 30 (1982) 1389-1395.

18) S. J. Andersen: Met. Mater. Trans. A 26A (1995) 1931-1937.

19) S. J. Andersen, H. W. Zandbergen, J. Jansen, C. Traeholt, U. Tundal and O. Reiso: Acta Mater. 46 (1998) 3283-3298.

20) K. Matsuda, S. Tada and S. Ikeno: J. Electron Microsc. 42 (1993) 1-6.

21) K. Matsuda, S. Ikeno and S. Tada: J. Japan Inst. Metals 57 (1993) 11071113.

22) A. K. Jena, A. K. Gupta and M. C. Chaturvedi: Acta Metall. 37 (1989) 885-895.

23) H. Suzuki, M. Kanno and Y. Shiraishi: J. Japan Inst. Light Metals 28 (1978) 233-240.

24) Y. Ohmori, Doan Chau Long, Y. Matsuura, K. Nakai and S. Kobayashi: Mater. Trans. 42 (2001) No. 12 in press.

25) H. E. Kissinger: Anal. Chem. 29 (1957) 1702-1706. 
26) W. A. Johnson and R. F. Mehl: Trans. AIME 135 (1939) 416-442.

27) M. Avrami: J. Chem. Phys. 7 (1939) 1103-1112.

28) J. W. Edington: Monographs in Practical Electron Microscopy in Materials Science, 3 Interpretation of Transmission Electron Micrographs, (Philips Technical Library, Philips, Gloeilampenfabrieken, Eindhoven, (1975) pp. 32-36.

29) K. Matsuda, S. Tada and S. Ikeno: J. Electron Microsc. 42 (1993) 1-6.

30) K. Matsuda, S. Tada and S. Ikeno: J. Japan Inst. Metals 58 (1994) 252 259.

31) J. M. Papazian: Metall. Trans. A 19A (1988) 2945-2953.

32) H. Suzuki, M. Kanno and G. Itoh: J. Japan Inst. Light Metals 30 (1980) 609-616.

33) Doan Chau Long, Y. Ohmori and K. Nakai: Mater. Trans., JIM 41 (2000) 300-305.
34) Kinzoku Data Book: Japan. Inst. Metals, Sendai, Japan (1994) p. 20.

35) The data referred in the book "Kinzoku Butsurigaku Joron" (Introduction to Metal Physics) written by Y. Koda, (1973), Corona Publishing Co., Japan, p. 93. These data were originally obtained by Bradshaw-Pearson (1957), Gatto-Federichi (1957), PanseriFederichi (1958), Kino-Kabemoto(1958), DeSorbo-Turnbull(1959), Detert-St_nder (1961), Okazaki-Takamura (1963), Kino et al. (1963) and Bass (1967).

36) M. Murayama and K. Hono: Acta Mater. 47 (1999) 1537-1548.

37) K. Matsuda, T. Yoshida, T. Wada, M. Yoshida, Y. Uetani, T. Sato, A. Kamio and S. Ikeno: J. Japan Inst. Metals 62 (1998) 718-726.

38) H. Suzuki, M. Kanno and G. Itoh: J. Japan Inst. Light Metals 28 (1982) 290-293 